\title{
EMERGENCIA JURÍDICA Y OBJETIVIDAD. REFLEXIONES FILOSÓFICAS EN TORNO AL CONTROL JUDICIAL DEL PRESUPUESTO HABILITANTE*
}

\author{
Matías Parmigiani \\ Universitat de Girona, Universidad Nacional de Córdoba, CONICET
}

RESUMEN. Realizo en el presente trabajo una revisión de la doctrina judicial prevaleciente en una parte importante de lberoamérica con respecto al control del «presupuesto habilitante» en el que descansa la legislación de emergencia. Según la doctrina en cuestión, a menos que haya un evento, hecho, circunstancia o situación de emergencia objetivamente comprobable, ninguna ley de emergencia podrá ser convalidada en sede jurisdiccional. A la hora de fundamentar esta exigencia, sin embargo, la doctrina parece realizar una serie de presuposiciones filosóficas de dudosa justificación. Mi cometido será doble: por un lado, consistirá en reconstruir qué entiende la doctrina por «objetividad»; y, por el otro, consistirá en criticar esta noción, en particular por estar ligada a una comprensión valorativamente aséptica de la función política difícilmente defendible.

Palabras clave: emergencia jurídica, control judicial, objetividad, valoración.

\section{Legal Emergency and objectivity. Philosophical Reflections on the Judicial Control of the Facts}

ABSTRACT. In the present paper I try to conduct a general review of the legal doctrine prevailing in an important part of Iberoamérica, especially regarding the control of the facts that underlie emergency legislation. According to the doctrine under analysis, unless an event, fact, circumstance or situation proves to be objectively verifiable, no emergency law would reunite the conditions to be validated by the judiciary. However, when it comes to understand what such requirement means to the doctrine, some dubious philosophical assumptions are put on display. My task is twofold: firstly, it is to reconstruct what the doctrine really means by "objectivity»; and, secondly, it is to criticize this notion, for being linked to a value-free conception of political action hardly appealing.

Keywords: legal emergency, judicial control, objectivity, valuation.

* Fecha de recepción: 7 de noviembre de 2015. Fecha de aceptación: 10 de junio de 2016. 
Matías Parmigiani

\section{A MODO DE INTRODUCCIÓN: LA EMERGENCIA JURÍDICA Y EL CONTROL DEL PRESUPUESTO HABILITANTE}

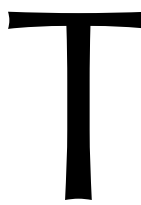

odo sistema jurídico supone la posibilidad de regular la conducta humana en procura de tornar más previsible - y pacífica, según sería de esperar - la vida de una comunidad (cfr. ALCHOURRÓN y BuLYGIN, 2002: 202; asimismo, Orozco Henríquez, 2003: 300; Comanducci, 1999: 98). Más aún, tan básica y elemental es la función de la previsibilidad que la noción misma de «Estado de derecho», con todas las garantías individuales que de ella se siguen, parece presuponerla conceptualmente (RAZ, 2001; FERRAJOLI, 2001: 36 y ss. y ÁvILA, 2012: 91-92).

Entre las normas que componen un ordenamiento jurídico, las hay de diferentes clases: normas que prohíben, normas que obligan, normas que permiten y normas que facultan la realización de ciertas conductas. Dentro de esta última clase de normas, existe en algunos países una tipología muy particular. Por medio de ella, los poderes políticos del Estado — sean estos el Poder Ejecutivo o el Poder Legislativo- son facultados a declarar una emergencia pública cuando ciertas condiciones excepcionales tornan inaplicable la legislación imperante. Con la declaración de una emergencia pública, surge el denominado «derecho de la emergencia», que puede ser definido como un sistema de normas caracterizado por al menos cuatro notas distintivas: $a$ ) es dictado para resolver una coyuntura; $b$ ) su tratamiento escapa de los canales ordinarios previstos para la sanción de normas; $c$ ) sus disposiciones se apartan de las de aquel sistema de normas previsto para funcionar en la normalidad; y d) su aplicación usualmente supone la generación de consecuencias desfavorables para todos o algunos de sus destinatarios (en el sentido que supone la privación de algún bien de los mismos) que no se encontraban previstas en el sistema de normas establecido para tiempos de normalidad ( $c f r$. GUIBOURG, 2003: 6-9).

Que este derecho exista en algunos países ya resulta de por sí una cuestión que levanta una inmensa polvareda filosófica. Por definición, el derecho de emergencia viene a plantear, como dice Ciuro CALDANI, «una ruptura de la lógica positiva de las normatividades por la crisis de los casos planteados en sus antecedentes», negándose mediante este derecho «lo que en principio se promete» (Ciuro CALDANI, 2007: 37). Por la misma razón, la existencia de un instituto como este en el entramado de un Estado de derecho suscita una paradoja inocultable: si lo propio del estado de emergencia (o excepción, como también usualmente se lo denomina) es, al decir de AGAMBEN, «una suspensión (total o parcial) del ordenamiento jurídico, ¿cómo puede tal suspensión estar comprendida en el orden legal? ¿Cómo puede una anomia estar inscripta en el orden legal?» (AGAMBEN, 2007: 59).

A fuer de ser honestos, debe aclararse que el derecho de la emergencia ha estado y aún está presente incluso en aquellos ordenamientos jurídicos carentes de cláusulas regulatorias expresas. Por razones consuetudinarias, prudenciales y de diversa índole, la invocación de este derecho por parte del poder político pudo ser $-\mathrm{y}$, en algunas circunstancias, de hecho ha sido - perfectamente capaz de obtener las mismas credenciales de legitimidad que usualmente detenta la invocación del derecho ordinario 
expresamente regulado ( $v i d$. AgAmBEn, 2007: 37) ${ }^{1}$. En contraposición a esta suerte de optimismo permisivo, todavía pervive en la memoria de muchos el eco resonante del art. 48 de la Constitución de Weimar y las consecuencias políticas nefastas que su utilización por sucesivos gobiernos trajo aparejadas. Pero más allá de estas particularidades históricas y los análisis que susciten, lo cierto es que gran parte de nuestros actuales sistemas constitucionales contienen provisiones de emergencia expresas. Resulte o no paradójica la inscripción de la anomia en el orden legal, todo parece indicar que este tipo de diseño normativo no persigue otro objetivo que el de contener hasta donde sea posible el grado de anomia admitido mediante una limitación de la discrecionalidad del Poder Político.

Tómense por lo pronto dos casos como indicadores: el de la vigente Constitución Argentina y el de la (asimismo vigente) Constitución Española. En el primer caso, la potestad de apelar al instituto de la emergencia está consagrada en los arts. 23 (sobre el estado de sitio), 76 (referido a la emergencia pública cuando habilita - excepcionalmente- en el Ejecutivo la delegación legislativa) y 99, inc. 3 (referido a la potestad presidencial de dictar decretos de necesidad y urgencia). Este último artículo sostiene que el Poder Ejecutivo solo podrá emitir disposiciones de carácter legislativo «cuando circunstancias excepcionales hicieran imposible seguir los trámites ordinarios previstos por la Constitución para la sanción de las leyes, y no se trate de normas que regulen materia penal, tributaria, electoral o de régimen de los partidos políticos». A estas restricciones de carácter material, el artículo añade otras de carácter formal o procedimental, entre las que cabe mencionar la exigencia de que los decretos sean decididos en acuerdo general de ministros, el lapso en el que la medida debe ser sometida por el Jefe de Gabinete de ministros a consideración de la Comisión Bicameral Permanente, o el tiempo y el modo en el que ella debe ser tratada por esta misma comisión.

En el caso de la Constitución Española ocurre algo similar. La apelación al instituto de la emergencia ha sido consagrada por los arts. 116 (sobre los estados de alarma, de excepción y de sitio) y 86 (referido, una vez más, a la potestad presidencial de dictar decretos de necesidad y urgencia). Lo que establece este segundo artículo es que las disposiciones legislativas provisionales que dicte el Gobierno «no podrán afectar al ordenamiento de las instituciones básicas del Estado, a los derechos, deberes y libertades de los ciudadanos regulados en el Título I, al régimen de las Comunidades Autónomas ni al Derecho electoral general» (inc. 1). Por otro lado, los dos incisos restantes (inc. 2 y 3 ) fijan los requisitos formales que todo Decreto-ley debe satisfacer, como su plazo máximo de envío al Congreso o los tiempos que este puede tomarse para su convalidación o derogación.

Otros casos tanto dentro como fuera de Iberoamérica podrían haberse tomado como botones de muestra. El resultado sería el mismo. Según me atrevo a aventurar, en casi todos ellos se constataría lo que estos ejemplos ponen en evidencia, a saber: que la potestad de dictar legislación de emergencia está condicionada por la presencia

1 Jurisprudencialmente los antecedentes sobran. Por ejemplo, en la República Argentina, antes de la sanción de la Constitución de 1994 que vino a regular el dictado de decretos de necesidad y urgencia, varias leyes de emergencia fueron avaladas por el Poder Judicial. Vid. al respecto el volumen de la Corte Suprema de Justicia, Decretos de necesidad y urgencia: Secretaría de Jurisprudencia, Primera Edición, Buenos Aires: Corte Suprema de Justicia de la Nación, agosto de 2010. 
Matías Parmigiani

de resguardos de tipo procedimental y sustantivo claramente delimitados. Por si fuera poco, estos mismos resguardos previstos en nuestros textos constitucionales suelen ir acompañados de legislación anexa tendente a especificar aún más su naturaleza. En Argentina, tal es el caso de la Ley 26.122 (sancionada el 20/07/2006 y promulgada el 27/07/2006); en España, lo mismo sucede con el art. 151 incorporado en el Título VI («Del control sobre las disposiciones del Gobierno con fuerza de ley») del Reglamento del Congreso de los Diputados (promulgado el 10/02/1982).

Aquí, sin embargo, no me ocuparé de ninguno de estos resguardos. Aunque las limitaciones materiales constitucionalmente impuestas a la potestad de promulgar legislación de emergencia seguramente generarán dificultades (pienso, por ejemplo, en la dificultad interpretativa que podría suscitar en Argentina la cuestión de delimitar si una tasa es un tributo u otras análogas) y aunque los requisitos procedimentales previstos puedan resultar igualmente vagos, ambiguos o hasta insuficientes (en Argentina, a diferencia de España, cuando un decreto no es tratado por la Comisión Bicameral Permanente se considera tácitamente convalidado, lo cual no está contemplado expresamente en ley alguna), a mi juicio ninguno de esos problemas reviste la complejidad e importancia que recubren al tercer requisito o resguardo, hasta aquí omitido. Me refiero al denominado «presupuesto habilitante», título con el que la doctrina general intenta capturar la exigencia de que para que una ley de emergencia resulte convalidada, dicha ley debe hacer referencia a un evento, hecho, circunstancia o situación de emergencia objetivamente comprobable.

El cometido principal que busco en el presente trabajo es doble. Por un lado, consiste en reconstruir el significado de esta exigencia tal cual ella ha sido interpretada por la doctrina judicial prevaleciente en buena parte de Iberoamérica. En este sentido, la formulación elegida no es casual. Una razón de fecundidad teórica aconseja contar con una interpretación aproximativa ciertamente amplia de la exigencia, que es lo que aquel dictum pretende consagrar. Esto se puede apreciar al menos en dos planos distintos. En primer lugar, al hablar de «convalidación» sin más precisiones, el dictum guarda un precavido silencio sobre cuál sea la instancia encargada de realizarla. En la mayor parte de los sistemas constitucionales de Iberoamérica y, en particular, en los de Argentina y España (que son, junto a Colombia, aquellos a los que remitirán mis ejemplos), dado que lo usual es que las medidas de emergencia sean dictadas por la autoridad ejecutiva, su legitimidad suele depender mayormente de lo que se decida en sede parlamentaria, lo que no obsta a que en algunos casos puntuales se alcance el terreno judicial ${ }^{2}$. No obstante, incluso si este no fuera el caso, una fórmula más acota-

2 En Argentina, país en el que impera un control difuso de constitucionalidad, esto suele suceder cada vez que un particular acude a sede judicial para reclamar por un derecho que la legislación de emergencia ha vulnerado o que podría llegar a vulnerar, en cuyo caso lo hará por vía de un recurso de amparo. En España, país en el que impera un control de constitucionalidad concentrado, los requisitos que deben cumplirse para acudir al Tribunal Constitucional son más restrictivos. Por caso, la Ley Orgánica del Tribunal Constitucional español establece dos vías alternativas por las cuales puede promoverse una declaración de inconstitucionalidad: a) el recurso de inconstitucionalidad y b) la cuestión de constitucionalidad, designando a su vez qué actores institucionales están autorizados para participar en ellas. Tal como establece el art. 32 de la citada Ley, la primera vía podrá transitarse cuando la sospecha de inconstitucionalidad se suscite a propósito de los Estatutos de Autonomía y demás Leyes del Estado, orgánicas o en cualesquiera de sus formas, y disposiciones normativas y actos del Estado o de las Comunidades Autónomas con fuerza de ley, Tratados Internacionales y Reglamentos de las Cámaras y de las Cortes Generales. En estos casos, la promoción del recurso de inconstitucionalidad 
da no permitiría contemplar lo que sucede en un régimen como el colombiano, en el cual está estipulado que la autoridad política debe remitir cualquier ley de emergencia directamente al Tribunal Constitucional para su evaluación inmediata ${ }^{3}$.

Pero más importante todavía es el segundo plano de fecundidad teórica en el que se mide el dictum. Al elegir un término como «comprobable» (un término equivalente podría ser «verificable') en lugar de otro como «existente», el dictum tampoco prejuzga el tipo de objetividad que podría hallarse en cuestión. Y aquí es precisamente donde se refleja el segundo aspecto de mi doble cometido, el cual consiste ni más ni menos que en criticar la definición restrictiva de la objetividad que parece adoptar gran parte de la doctrina tribunalicia hoy vigente. Hacia la sección 5 de este trabajo (cfr. infra), espero arribar a una fórmula que sea capaz de consagrar de manera clara y sintética cuáles son los compromisos en materia epistémica y ontológica que asumiría esta doctrina a la hora de realizar un control objetivo del presupuesto habilitante. Según intentaré ponerlo en evidencia ( $c f r$. sección 4 ), los compromisos asumidos tenderán a variar a la sazón de los intereses políticos que se encuentren en juego. Con todo, la fisonomía general del discurso que se plasma en los fallos ( $c f r$. sección 2) permitiría inferir que, en el fondo, lo que anima a nuestros tribunales es un credo ingenuamente realista, partidario de una noción de «objetividad» axiológicamente aséptica (cfr. sección 3). El cometido principal de este trabajo, según he dicho, procura ser tanto reconstructivo como crítico. Pues bien, estos dos aspectos están íntimamente conectados, ya que es solo luego de que una reconstrucción formal nos permita ver de manera cristalina cuáles son las implicancias filosóficas adosadas a la concepción doctrinal de la objetividad en materia de emergencia, que llegaremos a apreciar dónde residen los principales motivos de preocupación ( $c f r$. secciones 6 y 7 ).

\section{EL PRESUPUESTO HABILITANTE SEGÚN LA DOCTRINA JUDICIAL LATINOAMERICANA}

El día 30 de julio del 2008, la Legislatura de la Provincia de Córdoba sancionó la ley 9504 en virtud de la cual se declaró la emergencia de la Caja de Jubilaciones, Pensiones y Retiros de la provincia. Tras aducir una merma de ingresos tributarios provocada por

\footnotetext{
constituye una potestad reservada a los siguientes órganos: a) El Presidente del Gobierno, $b$ ) el Defensor del Pueblo, c) 50 Diputados y d) 50 Senadores. En cambio, cuando esta sospecha se suscite en relación a Leyes, disposiciones o actos con fuerza de Ley del Estado que puedan afectar el ámbito de autonomía de las Comunidades Autónomas, las que estarán legitimadas para promover el recurso serán precisamente los órganos colegiados ejecutivos y las Asambleas de estas mismas Comunidades, previo acuerdo adoptado al efecto. Por su parte, con respecto a la segunda vía, relativa a cuestiones de inconstitucionalidad, ella está reservada para los Jueces y Tribunales, cuando actuando de oficio o a instancia de parte, consideren que una norma con rango de Ley aplicable al caso y de cuya validez dependa el fallo pueda ser contraria a la Constitución.

3 Según está contemplado en la jurisprudencia de la Corte Constitucional de Colombia, el control de constitucionalidad de los estados de excepción y el ejercicio de los poderes que de allí emanan debe ser jurisdiccional, automático, integral y estricto, sin perjuicio del control político constitucionalmente previsto. En particular, el elemento de control automático mencionado comporta el deber por parte del Gobierno de enviar a la Corte Constitucional los decretos legislativos que dicte en uso de las facultades extraordinarias ni más ni menos que al día siguiente de su expedición. En caso de que esto no suceda, la Corte está facultada para aprehender su conocimiento actuando de oficio (sobre lo mismo, vid. la Sentencia C-156/11, 9 de marzo de 2011, Bogotá, DC).
} 
la crisis del campo y otros factores causales, el Gobierno de José Manuel de la Sota y la Legislatura de mayoría oficialista tomaron la iniciativa de recomponer la economía de la caja mediante una afectación de los beneficios (jubilaciones y pensiones) mayores a los 5.000 pesos, de manera tal que se pagaran parcialmente en pesos y parcialmente en títulos de deuda provincial. A raíz de esta medida, decenas de jubilados concurrieron a la justicia para hacer valer sus derechos, principalmente mediante la interposición de recursos de amparo. Una de estas causas recaería en manos del Tribunal Superior de Justicia de la provincia. Aunque el tribunal terminaría por convalidar la emergencia y rechazar el recurso, el resultado de su fallo no es lo relevante en este contexto. Lo relevante es el modo en que el tribunal abraza la doctrina según la cual los jueces poseerían la legítima facultad de controlar la existencia o no de la emergencia, más allá de cuál sea la valoración que le susciten los medios elegidos por la autoridad política para hacerle frente. Esto es lo que se desprende de su sentencia:

Parece claro que si verificar implica comprobar, acreditar, demostrar que los hechos invocados condicen con la realidad, esto de por sí trasunta un juicio intelectivo que excluye toda valoración discrecional. Importa la existencia o inexistencia de un hecho, la verdad o falsedad de una afirmación. De allí se deduce que el control judicial del presupuesto fáctico es hoy una realidad indiscutible, desde la incipiente jurisprudencia del Consejo de Estado Francés sobre la «exactitud material de los hechos», o su «constatación» como lo denomina la doctrina italiana («Bossio, E. Esther c/ Caja de Jubilaciones — Recurso de ApelaciónRecursos de Casación e Inconstitucionalidad», del 15/12/2009, en MJ-JU-M51906.AR, en bttp://ar.microjuris.com: Punto 9.V. del voto de la mayoría).

En franca consonancia con la línea de razonamiento adoptada por el tribunal argentino, la Corte Constitucional de Colombia también cree necesario diferenciar entre el elemento puramente intelectivo y el elemento de valor, ambos incluidos en la etapa de control del presupuesto habilitante. En efecto, tal como se desprende de varios de sus fallos, esa instancia es desagregada en tres elementos: (i) juicio de realidad de los hechos invocados, (ii) juicio de identidad de los mismos y (iii) juicio de sobreviniencia o inminencia de tales hechos. Ninguno de ellos comporta un supuesto valorativo, el cual solo se aboca a través de (iv) un juicio de gravedad de la perturbación y otro referido a la $(v)$ necesidad de las medidas extraordinarias. A tono con esta jurisprudencia, cabe citar el siguiente pasaje correspondiente a la sentencia que finalmente convalidaría Decreto Presidencial 4580 del 7 de diciembre del 2010, por el cual se declaraba el estado de emergencia económica, social y ecológica por razón de grave calamidad pública, emitido luego del paso del fenómeno de La Niña:

$\mathrm{El}$ «juicio de realidad» parte de ser un análisis eminentemente objetivo, tal y como lo señala la sentencia C-133 de 2009: «El presupuesto fáctico es susceptible de un juicio objetivo de existencia por parte del juez constitucional, quien debe determinar si los hechos invocados tuvieron ocurrencia. Se tiene entonces que la metodología que debe ser empleada es una verificación positiva de los hechos; por tanto, si efectivamente ocurrieron, el juicio objetivo de existencia se resuelve de manera positiva y en consecuencia la declaratoria del estado de conmoción interior, en lo atinente al primer presupuesto, es legítima; empero si el presupuesto fáctico no ha tenido lugar, esta primera constatación será negativa y en ausencia de este presupuesto, la declaratoria deviene en inconstitucional». No se trata entonces de un análisis de valoración de la alteración del orden social, económico y ecológico o de la circunstancia sobreviniente de los mismos, sino una verificación objetiva de la existencia de la amenaza o perturbación (Sentencia C-156/11, de la Corte Constitucional de Colombia, de 9 de marzo de 2011, Bogotá DC). 
Las dos sentencias que acabo de citar constituyen tan solo una muestra parcial de un universo mucho más extenso de casos. En tanto simples muestras que son, sin embargo, creo que ellas no solo resultan representativas de ese universo sino que consiguen transmitirnos con bastante luminosidad cuál es la ideología que tienen en mente algunos de los representantes más conspicuos del poder judicial iberoamericano cuando se disponen a llevar a cabo el control del presupuesto habilitante. Para los miembros del tribunal cordobés, es la existencia o inexistencia del hecho invocado por la autoridad política lo que debe corroborarse. Igualmente para los integrantes de la Corte colombiana, son los hechos invocados por la autoridad política los susceptibles de un «juicio objetivo de existencia». Los fallos de ambos tribunales, además, parecen girar sobre la idea de que al menos en lo que atañe a situaciones de emergencia, es perfectamente factible trazar una separación tajante entre lo fáctico de la situación y lo valorativo. Pero no solo eso. Aparentemente, si este no fuera el caso y lo valorativo y lo fáctico demostraran estar indisolublemente ligados, los magistrados temerían que el control del presupuesto habilitante en el que descansaría cualquier decreto-ley o legislación de emergencia pudiera condenarnos a las garras del más absoluto subjetivismo político. A su juicio, la separación, además de factible, es imperiosa.

\section{3. ¿UN OBJETIVISMO INGENUO? A PROPÓSITO DE LA IMBRICACIÓN «HECHO-VALOR'}

A los efectos de obtener una caracterización provisional del credo en cuestión, aquí simplemente lo llamaré, por una razón de economía semántica, «objetivismo ingenuo» (cfr. GONZÁlEZ LAGIER, 2005: 24-6; ANDRÉS IBÁÑEZ, 1992: 263). No obstante esta razón, los motivos para llamarlo así son al menos dos. El primero de ellos viene dado por algo que dice M. TARUFFO en el cap. 2 de La prueba de los hechos, destinado a deslindar el concepto de «hecho» y sus distintas clasificaciones. Entre varias de las contribuciones valiosas allí vertidas, TARUFFO analiza el perfil de aquellas normas que individualizan el hecho jurídicamente regulado mediante lo que WRÓBLEWSKI llama una «identificación valorativa», tal el caso de aquellas normas cuya prótasis está compuesta por expresiones como «daño grave», «justa causa» o «conducta reprobable» (cfr. 2002, 128; además, FERRER BELTRÁN, 2005: 49-53). Un caso especial de identificación valorativa que menciona TARUFFO se presenta cuando la individualización del supuesto fáctico solo se hace por referencia al criterio valorativo, no habiendo identificación alguna, siquiera vaga — nos dice-, referente al hecho que puede ser valorado negativamente. El supuesto de hecho no importa en sí mismo por alguna característica intrínseca, sino solo en cuanto produce «una consecuencia consistente en la violación de un valor», como ser «contrario a las buenas costumbres» o «antisindical» (ibid.: 129). A tenor de estos lineamientos, cabría decir que si la emergencia jurídica tal cual es regulada por nuestros ordenamientos constitucionales fuera clasificable como un supuesto de esta naturaleza, el credo que se desprende de sentencias judiciales como las citadas en la pasada sección sería, además de ingenuo, lisa y llanamente irrisorio. Sin embargo, puesto que conceder esta caracterización nos dejaría sin demasiadas motivaciones para seguir avanzando en este trabajo, aquí 
sostendré, por mor del argumento, que no es este el tipo de supuesto que los jueces tienen en mente ${ }^{4}$.

Por su parte, el otro motivo para tildar de ingenuo al objetivismo que se desprende del credo en cuestión está relacionado con algo que dice PUTNAM en el segundo capítulo de El desplome de la dicotomía hecho-valor y otros ensayos. Luego de preguntarse «por qué es tan tentadora la dicotomía hecho/valor», escribe:

es mucho más fácil decir «esto es un juicio de valor», en el sentido de que «no es más que una cuestión de preferencia subjetiva», que hacer lo que intentaba enseñarnos Sócrates: indagar quiénes somos y cuáles son nuestras convicciones más profundas, y someter estas convicciones a la exigente prueba de un análisis reflexivo (2004: 59).

Desde luego, este no es lugar para ensayar una crítica sobre cómo la autoridad judicial debería entender la actividad de valorar, ni tampoco para seguir a PUTNAM en su empeño por dotarla, inspirado en DEWEY, de la objetividad que una inmensa tradición filosófica le ha negado. No es tal cosa lo que busco aquí. Simplemente deseo remarcar dos cosas: en primer lugar, que aún si lo valorativo estuviera indisolublemente ligado a lo fáctico, esto no tendría por qué conminarnos a un subjetivismo ciego o radical ( $c f r$. DEWEY, 2008; WIGGINS, 1998a); y, en segundo lugar —lo que es mucho más importante-, que en la medida en que no reconozcamos qué comporta el predicado «emergencia» que califica a una situación como «de emergencia», difícilmente alcanzaremos a obtener una idea cabal de lo que comporta el concepto de «situación» que recibe dicho calificativo.

En este lugar, bien puede resultar útil traer a colación el modo como se comportan los predicados éticos densos, que son los que ocupan mayormente la atención de Putnam en este y en otros capítulos del mismo libro. Predicados como «cruel»o «generoso», por ejemplo, a diferencia de predicados como «bueno» o «incorrecto», tienen la particularidad de que unas veces pueden usarse en sentido descriptivo y otras en sentido prescriptivo. El problema que se suscita con estos predicados, que no es sino el problema que los positivistas lógicos, los no-cognitivistas y los prescriptivistas morales como HARE intentaron resolver infructuosamente ( $c f r$. ESQUIVEL, 1981: 6-12; WigGins, 1998b: 95-108; WiLLIAMS, 1997: 180-1), es que por más esfuerzos que dediquemos a la tarea de definir cuáles son las características descriptivas que deben estar presentes en una acción para que la misma reciba la calificación de cruel o generosa, siempre podremos encontrar acciones que sin compartir estas mismas características, resulten igualmente crueles o generosas.

En cierto sentido, estos intentos no hacen más que suscitar el argumento de la pregunta abierta de MOORE. Los ejemplos sobran. El propio PUTNAM alude a uno muy elucidario, por lo que voy a aprovechar la ocasión para apropiarme de él y reinventarlo. Supongamos que, imitando a HARE, osamos definir «cruel» como «aquello que causa hondo sufrimiento» e imaginamos como caso paradigmático de una acción cruel la que lleva a cabo el torturador Josef Mengele. A menos que al mismo tiempo consigamos precisar qué significan los términos «sufrimiento»y «hondo» sin invocar expresiones valorativas, la definición puramente descriptiva de cruel será insuficiente. Pero incluso

\footnotetext{
4 En Prueba y verdad en el derecho, Jordi FERRER ofrece la clave para una lectura alternativa. Retomo este punto en la Sección 6 de este trabajo (cfr. infra).
} 
en el hipotético escenario en el que nos las ingeniáramos para definir uno y otro término de manera puramente descriptiva, equiparando «sufrimiento» a «dolor físico» y «hondo» a, digamos, «todo aquello que sobrepasa un nivel $X$ de descarga neuronal», siempre habrá un caso de crueldad que no se corresponda con la definición. Quien «corrompe a una persona joven con el deliberado propósito de evitar que desarrolle un gran talento en algo», apunta PUTNAM, se estaría comportando de manera extremadamente cruel, «aun cuando la víctima nunca sienta un dolor manifiesto» (2004: 54).

Una sospecha que podría invadir a muchos es que el predicado «emergencia» quizá esté comportándose de manera similar a como se comportan predicados éticos densos como «cruel» o «generoso». Sin embargo, por más que esta sospecha sea cierta, creo que ella sería irrelevante para entender la idea que parece estar operando como directriz oculta detrás de sentencias judiciales como las citadas. Después de todo, no es que los magistrados desconozcan que el término «emergencia» está dotado de una innegable carga valorativa ${ }^{5}$. Lo que simplemente esperan -y así lo confirman numerosos pasajes de sus sentencias - es que la autoridad política, al momento de redactar el preámbulo que debe acompañar a un decreto-ley, se tome la molestia de señalar cuáles son los hechos que explican la necesidad del mismo. De manera que, a diferencia de lo que parece sugerir G. TUSSEAU en un importante ensayo, no sería una preocupación por la naturaleza esencial de la emergencia lo que movilizaría a los magistrados; ni siquiera sería una preocupación por ofrecer una definición en abstracto de la misma,

5 A juzgar por la jurisprudencia del Tribunal Constitucional de España, esto es innegable. El indisoluble componente político-valorativo que recubre a las decisiones en materia de emergencia ha sido expresamente reconocido en innumerables fallos, como lo documenta SSTC 38/2007, de 15 de febrero (FJ 6), remitiéndose a 189/2005, de 7 de julio (FJ 3) y a 329/2005, de 15 de diciembre (FJ 5), las que a su vez siguen resoluciones anteriores (SSTC 182/1997, de 28 de octubre, 11/2002, de 17 de enero y 137/2003, de 3 de julio). En todas estas resoluciones, se reconoce «el peso que en la apreciación de la extraordinaria y urgente necesidad ha de concederse al juicio puramente político de los órganos a los que incumbe la dirección del Estado», si bien se aclara que esto no debe conducir a entender el concepto de extraordinaria y urgente necesidad como una «cláusula o expresión vacía de significado» (SSTC 38/2007, FJ 6). En Argentina y Colombia tal vez la deferencia hacia el juicio subjetivo del órgano político sea menor. Con todo, nadie podría negar que se trata de un hecho reconocido. Así, por ejemplo, la Corte Constitucional de Colombia sostiene en su Sentencia C135 de 2009 que «el acto mediante el cual se declara un estado de excepción» es un acto político, estando como tal «sujeto a consideraciones de necesidad, oportunidad y conveniencia». En Argentina, por su parte, si bien la tendencia ha sido un tanto elusiva o cambiante, la doctrina por la que parece haberse decantado la Corte Suprema de Justicia de la Nación a la hora de evaluar el presupuesto fáctico permitiría diferenciar entre dos situaciones: aquellas en la que se imponen lo que la Corte denomina «criterios de mera conveniencia ajenos a circunstancias extremas necesidad» - a los que, desde ya, descarta de plano- (al respecto, vid. Verrochi, Ezio D. c/Poder Ejecutivo Nacional-Administración Nacional de Aduanas, Fallo 322:1726 de 19/08/1999), y aquellas en las que las consideraciones que priman revisten un grado tal de complejidad fáctica y técnica que los jueces no se verían facultados «para sustituir a la administración en la determinación de las políticas o en la apreciación de los criterios de oportunidad» (Provincia de San Luis c/Estado Nacional, Fallo 326:417 (30) de 05/03/2003, voto en disidencia de los ministros Belluscio, Boggiano y Maqueda, considerandos 30 y 31 ; a su vez, véanse los fallos 308:2246, considerando $4 .^{\circ}$, y 311:2128, entre muchos otros). Desde luego, este tipo de deferencia practicada por la Corte hacia el órgano político, más que una admisión del componente valorativo indisociablemente ligado a la emergencia, parece connotar un reconocimiento de la superioridad epistémica de este órgano en ciertos asuntos, que no es lo mismo. Suponiendo que así sea, creo que aun sería posible comprobar una admisión por parte de la Corte del componente irreductiblemente valorativo de la emergencia en la elección de los medios específicos que realiza la autoridad política para hacerle frente. La misma sentencia que acabo de citar es elocuente al respecto: «En rigor, al Poder Judicial le está vedado jugar el acierto o error de decisiones que incumben al área de política económica» (considerando 55 del voto de la mayoría). En esta materia, lo único que la Corte está facultada para controlar es la razonabilidad de los medios empleados, es decir, que ellos resulten equitativos y justos (vid. una vez más el mismo considerando). 
como si esto pudiera hacerse per genus proximum et differentiam specificam (cfr. 2011: 513-515). En realidad, lo que parece movilizarlos es algo mucho más concreto. Se trata, para decirlo en resumidas cuentas, de la preocupación por impedir que la autoridad política se atreva a apelar sin más al instituto de la emergencia, esto es, sin que previamente haya mediado un hecho o situación concreta que todos podamos reconocer como objetivamente existente.

Ahora bien, ¿qué significa que un hecho o situación sea objetivamente existente? ¿Significa que ha de prescindir de toda valoración, como sugiere el tribunal cordobés de manera explícita? Incluso concediéndole a la doctrina que la propiedad (¿intrínsecamente?) valorativa de «emergencia» deba quedar afuera de la caracterización del elemento situacional ínsito en la expresión «situación de emergencia», ¿de qué tipo habrán de ser las características, rasgos o propiedades que deberían estar presentes en el hecho, evento, circunstancia o situación concreta invocada para que la misma pueda recibir, acto seguido, el calificativo de «emergencia'? Como quedara de manifiesto a partir del ejemplo de PUTNAM, las características o propiedades de un hecho o acción cualquiera a menudo solo podrán ser descritas empleando un vocabulario de inevitable carga valorativa, aun cuando ellas no tengan nada que ver con el predicado valorativo que propiamente se denomina «emergencia». Confío en que luego de un pequeño rodeo podamos arribar a una respuesta.

\section{4. ¿UN OBJETIVISMO DIFERENCIAL?}

En esta sección, deseo oponer a la caracterización provisional del credo efectuada en la pasada sección una caracterización que considero más justa. Para ello procederé en dos etapas. En la sub-sección 4.1), buscaré auxilio terminológico en la obra de John SEARLE al objeto de apropiarme del material necesario para recalificar la noción de objetividad y reposicionarla de cara a la discusión sobre el control judicial del presupuesto habilitante. En la sub-sección 4.2), por otro lado, me valdré de esta terminología para identificar qué dos tipos de objetividad podrían hallarse en cuestión cada vez el Poder Judicial se arroga la facultad de controlar las decisiones del Poder Político. La pasada sección mostró que un concepto valorativamente aséptico de objetividad no constituye su mejor exponente. La presente sección pretende ofrecer como alternativa a dicha clase de objetividad lo que aquí denominaré una objetividad diferencial, la cual estaría mejor dotada para posicionar a la autoridad judicial de cara a la autoridad política. Sin embargo, dado que las materias de la realidad sobre las cuales esta clase de objetividad puede medirse constituyen un universo por demás reducido, el objetivismo diferencial que se vale de ella tampoco se mostraría como una alternativa superadora.

\subsection{Propiedades intrínsecas y extrínsecas}

Existe una doble distinción que suele rendir importantes frutos filosóficos. En la modalidad en que deseo introducirla, ella ha sido intuitivamente moldeada por John SEARLE en La construcción de la realidad social y en otros trabajos, si bien considero que algunas de las definiciones que la han acompañado pueden ser en extremo desorien- 
tadoras. A propósito de la distinción objetivo-subjetivo, SEARLE diferencia entre un sentido epistémico y uno ontológico. «Epistémicamente hablando, "objetivo" y "subjetivo" son básicamente predicados de juicios» (1997: 27), escribe. Así, cuando decimos que «Rembrandt es mejor artista que Rubens», por ejemplo, estaríamos formulando un juicio subjetivo, ya que su verdad o falsedad - agrega no sin cierta circularidadno pueden fijarse objetivamente. Juicios como estos no refieren, en opinión de SEARLE, a simples cuestiones de hecho, sino que dependen de ciertas actitudes, sentimientos y puntos de vista de los proferidores o de los oyentes de los juicios en cuestión. Un juicio como «Rembrandt vivió en Ámsterdam en el transcurso del año 1632», en cambio, resulta epistémicamente objetivo puesto que el hecho en el mundo que lo convierte en verdadero o falso es independiente de las actitudes o sentimientos que cualquiera pueda albergar al respecto.

En cuanto al sentido ontológico de la distinción, «objetivo» y «subjetivo» «son predicados de entidades y tipos de entidades - escribe SEARLE-e imputan modos de existencia». De esta manera, continúa, los dolores son entidades ontológicamente subjetivas, «porque su modo de existencia depende de que sean sentidos por los sujetos. Pero las montañas [...] son ontológicamente objetivas porque su modo de existencia es independiente de cualesquiera perceptores o de cualquier estado mental» (1997: 27).

Deudora de esta doble distinción que acabo de resumir es una tercera distinción añadida por SEARLE: la que se da entre aquellos rasgos del mundo que son intrínsecos y aquellos otros que son relativos al observador. Los primeros existen independientemente de nosotros, como por ejemplo las montañas y las moléculas. Los segundos, en cambio, dependen de nosotros para su existencia, ya que guardan «relación con la intencionalidad de los observadores, usuarios, etc.» (1997: 28). El ejemplo favorito de SEARLE es el del destornillador. Aunque este elemento posee ciertos rasgos intrínsecos, como la madera o el metal de los que está fabricado, es la función de «servir como» que extrínsecamente le imputan los usuarios lo que lo habilita a ser lo que es. Este carácter relativo que poseen algunos objetos y propiedades, sin embargo, no impide que los juicios que pronunciamos sobre ellos sean susceptibles de verdad o falsedad. Para ello, no es necesario que estos rasgos sean ontológicamente objetivos sino que basta con que sean objetivos desde el punto de vista epistémico ${ }^{6}$.

La importancia de esta triple distinción se pone especialmente de manifiesto a la hora de calificar los hechos sociales y las propiedades y/o hechos institucionales

\footnotetext{
${ }^{6}$ Debe aclararse que las propiedades intrínsecas y extrínsecas de la clasificación de SEARLE no se corresponden con lo que en la literatura metafísica se ha dado en llamar «propiedades intrínsecas y extrínsecas» de las cosas (al respecto, especialmente instructivos son los trabajos de CHISHOLM, 1976; KIM, 1982; LEWIS, 1983; VALLENTYNE, 1997 y LANGTON y LEWIS, 1998). Según la primera clasificación, la relatividad característica de las propiedades extrínsecas es una relatividad agencial. Según la segunda clasificación, en cambio, la relatividad agencial de las propiedades extrínsecas constituye tan solo un tipo de relatividad entre otros, y ni siquiera el más interesante. Con respecto a las propiedades intrínsecas, la correspondencia quizá sea mayor, aunque conviene notar que las propiedades relacionales también son susceptibles de caracterizarse a su vez como extrínsecas o intrínsecas (al respecto, vid. LEWIS, 1999: 129 y ss.), una posibilidad que en la clasificación de SEARLE está proscripta. La única relatividad que SEARLE está dispuesto a concederle a las propiedades intrínsecas de las cosas es una relatividad del tipo conceptual. La misma, sin embargo, en absoluto estaría en condiciones de conmover el realismo externo que SEARLE defiende, a pesar de los esfuerzos acometidos en esta dirección por Goodman, Putnam y otros filósofos (cfr. SEARle, 1997: 169 y ss.).
} 
en las que ellos descansan. Un hecho social como un «fenómeno inflacionario», una «corrida de acreedores» o una «elección presidencial», solo puede existir porque existen de manera previa una serie de hechos o propiedades que constituyen su condición de posibilidad. Así, por ejemplo, para que pueda darse eso que conocemos como «inflación», al menos es necesario que existan cosas tales como la moneda, el intercambio comercial o la propiedad. En la tradición filosófica, hace mucho tiempo que estas cosas se conocen con el nombre de «hechos institucionales» y evidentemente ha sido un mérito indudable de SEARLE el explicar de manera instructiva no solo cómo se generan sino también cuál es el lugar que ocupan en el anterior esquema de distinciones.

En cuanto a lo primero, aquí seré muy sintético. Para que un hecho institucional se genere, se requieren al menos tres elementos: la asignación de una función, la intencionalidad colectiva y las reglas constitutivas. Sólo por utilizar el ejemplo favorito de SEARLE, para que un simple trozo de billete adquiera la identidad de «dinero» y pueda funcionar como tal, se requiere de un acto constitutivo (tácito o expreso) en virtud del cual X, que posee ciertos rasgos físicos por ser un hecho bruto, cuente como Y (dinero) en $\mathrm{C}$ (una comunidad determinada) y pueda cumplir las funciones que típicamente cumple el dinero, como por ejemplo oficiar de medio de intercambio de bienes o servicios, constituir una provisión de valor, etc. De no reinar una suerte de acuerdo colectivo sobre el modo en que $\mathrm{X}$ ha de comportarse, $\mathrm{X}$ no sería el hecho institucional específico que denominamos dinero. De manera análoga, si quien empleara la regla constitutiva para transformar a $\mathrm{X}$ en dinero no fuera una autoridad a la que colectivamente se le concede la competencia específica para hacerlo (en Estados Unidos, por ejemplo, la Reserva Federal), tampoco X contaría como dinero en C (cfr. SEARLE, 1997: cap. 2).

Sobre lo segundo, digamos que si un hecho social como la inflación existe, es porque existen cada uno de los fenómenos institucionales que son su condición de posibilidad $^{7}$. Y si existen estos fenómenos sociales, solo puede ser porque existen a su vez una serie de hechos brutos a los que los miembros de una comunidad les han asignado una función valiéndose de ciertas reglas constitutivas ${ }^{8}$. Esta relatividad de los hechos institucionales (y, por derivación, también de los hechos sociales) es lo que los hace ontológicamente subjetivos, sin que esto implique negarles objetividad epistémica.

7 La distinción entre hechos o fenómenos «institucionales» y hechos o fenómenos «sociales» no es de SEARLE sino mía. No obstante, en Making the Social World encontramos una distinción análoga, para cuyo trazado se emplea otra terminología. SEARLE denomina a los primeros «hechos institucionales de base» [ groundfloor institutional facts] y a los segundos «hechos derivados de hechos institucionales relativos a terceras personas» [third person fallout facts from institucional facts] (cfr. 2010: 116). Además, cita con aprobación a Asa ANDERSSON, quien en Power and Social Ontology se refiere a los primeros con la denominación de «hechos institucionales micro» y a los segundos con la denominación de «hechos institucionales macro» (ibid.: 116). La importancia de esta distinción se explica para SEARLE porque nos faculta a hablar de una serie de hechos institucionales de los que los miembros de una comunidad no tienen por qué ser conscientes: «Así, por ejemplo, una economía podría ingresar en una recesión o atravesar las etapas de un ciclo económico — constata SEARLE - sin que los miembros de la comunidad tengan siquiera los conceptos de recesión o ciclo económico» (ibid.: 116). Hacia el final de este trabajo volveré sobre la importancia de esta distinción conceptual.

8 Escribe SEARLE en La construcción de la realidad social: «Es una consecuencia lógica del argumento principal de este libro que no pueda haber hechos institucionales sin hechos brutos» (1997: 197). 


\subsection{Las propiedades de los hechos y la ubicuidad política del juez}

Luego de este rodeo, creo que por fin estamos mejor posicionados para retomar las preguntas con las que finalizamos la sección anterior. A la luz de las distinciones efectuadas con ayuda de SEARLE, ¿cómo cabría entender la objetividad a la que aluden los magistrados en sus fallos? ¿En qué sentido los juicios intelectivos sobre los presupuestos fácticos en los que descansan las leyes de emergencia habrían de resultar objetivos? Que por lo menos se caracterizan por ser epistémicamente objetivos no es difícil de comprender. La objetividad epistémica es una propiedad que está presente tanto en aquellos juicios que son relativos a hechos o rasgos del mundo intrínsecos u ontológicamente objetivos, como en aquellos juicios relativos a hechos o rasgos del mundo extrínsecos u ontológicamente subjetivos, tal el caso de los hechos institucionales y sociales.

Con respecto a la primera tipología de juicios, la doctrina judicial parece conferirle un rol preeminente. En los casos paradigmáticos representados por las catástrofes naturales (terremotos, inundaciones, etc.), en general el control del presupuesto fáctico se realizará de manera epistémicamente objetiva siempre que los hechos referidos por la autoridad política sean ontológicamente objetivos, cuestión que no suele generar mayores dificultades, especialmente cuando estamos ante hechos a los que se les atribuye la entidad de ser públicos y notorios. Qué deba implicar una descripción puramente objetiva de estos hechos o cuáles son los hechos relevantes que deben ser descriptos y con qué grado de especificidad o precisión no son cuestiones para las que la doctrina haya formulado respuestas conclusivas ni uniformes, pero por el momento podemos hacer caso omiso de estos pormenores ${ }^{9}$.

El problema surge con respecto a la segunda tipología de juicios. Fenómenos sociales como crisis financieras, viales, migratorias o hasta político-representativas, además de que no remiten a entidades capaces de existir con independencia de la actitud que los seres humanos adopten hacia ellas - a diferencia de las catástrofes naturales, estos fenómenos son ontológicamente subjetivos-, suscitan observaciones de lo más diversas aun en el seno de una misma comunidad cultural, lo que suele generar controversias y desacuerdos muy difíciles de resolver. Al decir de WITTGENSTEIN, cuando uno de estos fenómenos hace aparición, «nunca es un tema referido a hechos de la ex-

9 La jurisprudencia del Tribunal Constitucional Español, en cambio, suele ser mucho más explícita al respecto. Vid., por caso, la STC 68/2007, de 28 de mayo, FJ 10. Por ahora, solo quisiera suscitar una reflexión. ¿En qué consiste el «presupuesto fáctico» de una ley de emergencia dictada para paliar las consecuencias generadas por una catástrofe natural? Como respuesta inmediata, cabe decir que no consiste solo en el fenómeno natural específico acontecido - sea, por caso, un terremoto- sino también en las propias consecuencias generadas por él. Entre los enunciados que integrarán el denominado presupuesto fáctico, entonces, encontraremos en un pie de igualdad tanto aquellos enunciados que refieran al fenómeno natural en cuestión (por ejemplo, al movimiento de las capas tectónicas medido por el sismógrafo) como aquellos que pretendan describir las propias consecuencias generadas a partir de este fenómeno, tal el número de víctimas, la cantidad de inmuebles afectados y otras del tipo. En principio, estos enunciados parecen incluir más bien pocos elementos valorativos. Sin embargo, si a ellos decidimos sumarle enunciados que hagan referencia, por ejemplo, al daño psicológico y moral padecido por los afectados o a la ruptura de las relaciones institucionales provocada por la tragedia, ya ingresaremos de lleno en otro terreno. ¿Quién podría negar que todos estos enunciados podrían formar parte del presupuesto habilitante con el mismo derecho que los enunciados estrictamente científicos que refieren al hecho natural? Siendo así, es difícil no preguntarse cómo la idea de construir un presupuesto fáctico que prescinda de toda valoración sea tan siquiera una empresa deseable. 
periencia (un problema de esos es siempre mucho más tratable), sino uno lógico y, por consiguiente, una cuestión gramatical propiamente dicha» (Zettel, 590). Comentando este pasaje, H. F. PITKIN reflexiona:

Tales controversias no se pueden resolver abandonando el nivel teórico y volviendo, en cambio, a la investigación empírica e histórica, ya que los mismos términos de la controversia aseguran que la llevaremos con nosotros hasta nuestros estudios empíricos e históricos, y que sus resultados serán igualmente ambiguos (1984: 452).

Pitkin (1984), CaVell (1979), Taylor (1997), Searle (1995), Murdoch (2001), BOURDIEU (2007), WiNCH (1994) y un sinnúmero de reputados filósofos, sociólogos y antropólogos inspirados en WITTGENSTEIN, piensan que la única manera de empezar a abordar estos problemas consiste en reconocer, para volver a citar a PUTNAM, que a menos que compartamos de algún modo «el punto de vista ético pertinente», nunca podríamos emplear razonablemente el término en cuestión (2004: 53). Hay una suerte de plexo común de vivencias y una capacidad de trasfondo sin la cual ningún entendimiento resultaría posible. Avanzar en esta dirección, sin embargo, nos distraería demasiado del camino que venimos transitando. Repárese por ahora solamente en el hecho de que el fenómeno de la relatividad valorativa de nuestros conceptos que tanto preocupa a la filosofía y que tanto debate ha generado entre filósofos y antropólogos en las últimas décadas ${ }^{10}$, no se produce solamente en esos más bien raros momentos de choque intercultural que preocupaban a WINCH, cuando las acciones de los otros nos resultan de una incomprensión tan manifiesta que nos vemos obligados a indagar en los estándares de racionalidad que manejan ( $c f r$. WINCH, 1994). Con aristas menos marcadas, un fenómeno muy similar a este llega a producirse aún en el interior de una misma comunidad discursiva, que comparte ciertos valores, vivencias y puntos de vista. Mientras un marxista como MANDEL vio la recesión mundial de 1974 como «el resultado de una fase típica de declinación en la tasa de ganancia» (1975: 20), un liberal ortodoxo quizá la viera como el efecto contingente del encarecimiento del petróleo después de la Guerra del Kippur. ¿Existe alguna solución para este tipo de disonancias?

Reviste sumo interés en este sitio notar que desde las ciencias sociales se han desarrollado alternativas tendientes a evitar estas controversias interminables, procurando disminuir el nivel de imprecisión de los términos en los que frecuentemente se instauran. Una de ellas, como PITKIN misma reconoce, ha consistido en introducir «definiciones operativas» de términos como «inflación», «recesión», «superpoblación», «tasa de crecimiento», «desarrollo económico», «poder», «legitimidad», «representación»y tantos otros que son habituales en ciencias sociales (PITKIN, 1984:, 396 y ss.). Mediante este tipo de definiciones, lo que generalmente se busca es, por decirlo parafraseando a HEMPEL, establecer una operación de testeo, T, que pueda ser llevada a cabo en cualquier caso al cual el término en discordia presumiblemente se aplique, y especificar un cierto resultado $\mathrm{R}$ de la operación cuya aparición sea considerada como el criterio para la aplicabilidad del término al caso dado (1979: 145).

10 Como dos claros exponentes de este debate aquí podríamos citar, de una parte, la discusión E. PRITCHARD, 1976; WINCH, 1972; 1994; MACINTYRE, 1972; 1977, que se produjo en el ámbito académico anglosajón a propósito de los azande; y, de la otra, la discusión que se dio en el mundo hispano, compilada por León OLIVÉ en Ética y diversidad cultural (1993). En ella, sobresale por su carácter polémico el texto de GARZÓN VALDÉS titulado «El problema ético de las minorías étnicas», con respuestas de L. VILLORO, D. SOBREVILLA y M. DASCAL, entre otras. 
Con el tiempo, muchas de estas mismas herramientas analíticas se incorporarían al dominio de la política. Cada vez que una comisión o cuerpo colegiado era creado por el partido gobernante de un Estado para investigar asuntos de carácter general, como la tasa de crecimiento económico o los índices de delincuencia, pero también asuntos de carácter más concreto como el asesinato del presidente J. F. Kennedy investigado por la Comisión Warren, estas herramientas estuvieron a la orden del día. Gracias a estos organismos y a las herramientas por ellos empleados, paulatinamente fue generándose un inestimable caudal de información que no solo supo dotar de mayor racionalidad y capacidad de previsión a la política legislativa, sino que también le permitió a la ciudadanía acceder a información fidedigna y confiable para evaluar con criterios menos sesgados las actuaciones de la clase dirigente ( $c f r$. MERTON, 1980: 186 y ss.).

En cierto sentido, cuando uno repasa algunos de los fallos en materia de emergencia más resonantes que se sucedieron en los últimos años, no puede dejar de advertir el peso adjudicado a la información obtenida en virtud de estos canales. La Sentencia C-156/11 de la Corte Constitucional de Colombia, sin ir más lejos, constituye un caso paradigmático. Sabido es que el paso del fenómeno meteorológico conocido como La Niña, sobre el que versó el Decreto Presidencial 4580/10, generó perjuicios tanto a nivel humano como económico que fueron públicos y notorios. Su acreditación, por ende, no presentaba mayores inconvenientes. Aun así, el Poder Ejecutivo de dicho país se encargó de justificar su declaratoria mediante rigurosos datos estadísticos provenientes de toda clase de organismos, como el Instituto de Hidrología, Meteorología y Estudios Ambientales, el Instituto Geográfico Agustín Codazzi en materia de inundaciones, el Ministerio de Hacienda y Crédito Público en materia de viviendas, o la Dirección de Tránsito y Transporte en materia de afectaciones viales. La información fue sumamente detallada y las fuentes confirmatorias, de lo más diversas. Como viene exigido por la Constitución, la Ley Estatutaria 137 de 1994 y el Decreto 2067 de 1991, el Gobierno cumplió en enviar a la Corte esta documentación y el texto del decreto al día siguiente de su expedición, de lo cual se seguiría una consecuencia fácilmente imaginable: la convalidación del decreto-ley. Sin embargo, más allá de este final previsible, el interrogante queda planteado: ¿cuál habría sido la reacción de la Corte si el Gobierno no hubiera procedido con semejante rigor formal? ¿Habría rechazado el decreto-ley solo porque el Gobierno adujera que ascendían a una cifra aproximada de 2.000.000 las hectáreas del sector rural inundadas, en lugar de las 1.324.289 que figuraban en el informe del Ministerio de Hacienda?

Interrogantes como estos creo que nos permiten apreciar con total nitidez cuál es la función real que desempeña el discurso sobre la objetividad empleado por la doctrina. A modo de explicación aproximativa, podría ensayarse la hipótesis de que mientras más difícil sea para los tribunales compartir la postura del órgano político, más proclives serán a esgrimir un concepto de objetividad cargado de fuertes tintes ontológicos. E, inversamente, mientras menos difícil sea para ellos compartir la postura del órgano político, menos reacios serán a apelar a un concepto de objetividad más próximo al plano epistémico. Dicha hipótesis, sin embargo, no resistiría el menor escrutinio. El discurso realista ontológicamente cargado que emplean nuestros tribunales se comprueba a lo largo y a lo ancho de todo el espectro jurisprudencial, aunque algunas veces se presente de forma matizada. Como no podía ser de otra manera, todo dependerá del tipo de fenómeno que se suscite. 
Ante la presencia de fenómenos de naturaleza meteorológica o incluso epidemiológica, la jurisprudencia tenderá a ser favorable a la voluntad del Poder Ejecutivo. Contrariamente a lo que podría imaginarse, esto no sucede porque los hechos invocados se correspondan con una realidad dotada de propiedades intrínsecas a las que todos tendríamos acceso. Lo que sugiere el interrogante antes abierto es que esto sucedería aún en el caso de que los hechos invocados en una descripción no se correspondieran con los hechos reales. Remitiéndonos al contraejemplo imaginado, cabe decir que si la cifra invocada por el Gobierno colombiano no se hubiera correspondido con la cifra real elaborada por el Ministerio de Hacienda y Crédito Público, esto probablemente no importaría, ya que las consecuencias de revocar un decreto destinado a palear las consecuencias de un fenómeno tan devastador serían mucho más negativas que las de convalidarlo. Son, pues, criterios evidenciales bastante menos estrictos los que muchas veces terminarán imponiéndose.

En cambio, cuando el fenómeno en cuestión revista un cariz político, social o económico, lo que por lo general tenderá a comprobarse es que ni bien los tribunales se muestren dispuestos a hacerle la venia al poder político, el fenómeno se describirá como dotado de una complejidad tal que las competencias epistémicas especiales que se requerirían para su verificación no serían distintivas del Poder Judicial (cfr. supra, nota núm. 5; asimismo, vid. el considerando 6.1.2 de la Sentencia C-156/11 del Tribunal Constitucional de Colombia). Por el contrario, si se tratara de diagnósticos que el Poder Judicial juzga equivocados, allí sí es probable que acontezca lo que aconseja la hipótesis y nuevamente pase a ser el concepto de objetividad cargado de tintes ontológicos el que saque a relucir su carta ganadora en el discurso.

\section{FINALMENTE, LA FÓRMULA DOCTRINARIA DE LA EMERGENCIA. ¿POR QUÉ NO?}

Por muy atractivos que sean estos análisis realistas y por mucho que hoy dominen la escena de la teoría politológica y jurídica más influyente, personalmente creo que ellos no tienen otro valor que el de ser instructivas especulaciones sin demasiado sustento empírico. Tanto desde un punto de vista teórico como desde un punto de vista práctico-normativo, me atrevo a sugerir que mucho más fructífera resultaría una tarea como la de intentar sistematizar en una fórmula definida qué cosa hacen de hecho nuestros jueces cuando apelan a la idea de objetividad, pues una fórmula tal podría brindar una herramienta irreemplazable a la hora de analizar de manera comparativa qué sucede en los distintos ordenamientos normativos. En última instancia, la mejor fórmula será aquella que resulte conciliable con una interpretación integral y coherente de lo que debería suceder entre los actores que intervienen en un ordenamiento jurídico cuando el instituto de la emergencia aflora a superficie. Poniéndolo en terminología rawlsiana, la mejor fórmula será precisamente aquella que alcance un equilibrio reflexivo en relación a nuestras intuiciones normativas más firmes o mejor respaldadas.

Por razones de espacio, pospondré para otra ocasión una defensa explícita de lo que, al menos a mi juicio, podría llegar a ser una fórmula superadora (cfr. PARMIGIANI, 2016). Lo que quisiera hacer en este sitio es valerme de las distinciones conceptuales 
previamente esbozadas a fin de sistematizar en una fórmula aproximativa lo que parece suponer la doctrina judicial bajo escrutinio. Ello, además, me dará pie para explicar por qué no resulta aceptable. Considérese el siguiente intento reconstructivo, válido para capturar el objetivismo ingenuo que describiera en la sección 3 de este trabajo:

\section{(E) Emergencia $=_{\text {df }(\text { Doctrina) }}$}

Para todo sistema normativo $\mathbf{S N}$ y ante un hecho, evento, circunstancia o situación $\mathbf{P}$, dotada de $\mathbf{N}$ propiedades o modos de ser característicos, $\mathbf{P}$ constituye objetivamente una situación de emergencia $\mathbf{E}$ si y solo si: a) la autoridad normativa $\mathbf{X}$ la instituye o declara como tal; $b$ ) no se constatan vicios desde el punto de vista formal; y c) dentro del universo de propiedades o modos de ser característicos que $\mathbf{P}$ posee, $\mathbf{P}$ reúne precisamente aquellas propiedades que la ley fija como presupuestos fácticos de la emergencia, más allá de cuáles sean las evaluaciones pertinentes de la autoridad normativa $\mathbf{X}$.

Así reconstruida, creo que la fórmula resulta contemplativa de los principales lineamientos sostenidos por la doctrina judicial en materia de emergencia. En particular la última parte de la fórmula es clave en este asunto, ya que tiene el mérito de enfatizar el compromiso con la asepsia valorativa que constituye su núcleo vital. No obstante, compruébese la disparidad de resultados que se obtienen ni bien alcanzamos a conferirle al requisito de la objetividad cualquiera de las siguientes dos interpretaciones posibles: de un lado, una interpretación ontológica; del otro, una interpretación en sentido meramente epistémico. Tras calificar a las propiedades o modos de ser característicos del hecho o situación por su calidad de intrínsecas o extrínsecas, se presentan dos alternativas en danza:

\section{$\left(E^{\prime}\right)$ Emergencia $=_{\mathrm{df}(\text { Doctrina I })}$}

Para todo sistema normativo $\mathbf{S N}$ y ante un hecho, evento, circunstancia o situación $\mathbf{P}$, intrínsecamente dotada de $\mathbf{N}$ propiedades o modos de ser característicos, $\mathbf{P}$ constituye objetivamente una situación de emergencia $\mathbf{E}$ si y solo si: $a$ ) la autoridad normativa $\mathbf{X}$ la instituye o declara como tal; b) no se constatan vicios desde el punto de vista formal; y $c$ ) dentro del universo de propiedades o modos de ser característicos que $\mathbf{P}$ posee intrínsecamente, $\mathbf{P}$ reúne precisamente aquellas propiedades que la ley fija como presupuestos fácticos de la emergencia, más allá de cuáles sean las evaluaciones pertinentes de la autoridad normativa $\mathbf{X}$.

En esta fórmula, que $\mathbf{P}$ esté objetivamente dotado de $\mathbf{N}$ propiedades o modos de ser característicos significa que dichas propiedades existen con independencia de los valores que detente cualquier ser humano en particular, trátese este de un ciudadano que haya sufrido la privación de un bien a causa de alguna disposición de la ley, o trátese en su lugar de la propia autoridad política que la haya sancionado. Ahora bien, si este fuera el caso, el hecho de que cierta autoridad normativa la haya instituido o declarado como tal (condición a) de la fórmula original), así como —en menor medida —el hecho de que no se constaten vicios desde el punto de vista formal (condición $b$ ) de la fórmula), ¿no se transformarían en resguardos o requisitos prescindibles?

A juzgar por lo que está constitucionalmente positivizado en nuestros ordenamientos jurídicos, resulta claro que no. Tal cual se viera en la sección introductoria de este trabajo (cfr. supra), el sitio que ocupan los resguardos formales y materiales en la práctica del control de constitucionalidad de las leyes de emergencia está firmemente asegurado. Sin embargo, si se aceptara la interpretación restrictiva que esta fórmula propone para entender la naturaleza del presupuesto habilitante, cargada de tintes ontológicos 
ingenuamente realistas, creo que la doctrina se quedaría sin demasiados argumentos para explicar por qué nuestros ordenamientos constitucionales designan a la autoridad política, y no a otra instancia (por ejemplo, a una instancia dependiente del Poder Judicial o a una entidad técnica dotada de cierto nivel de autonomía), como la única facultada para declarar una emergencia pública y actuar en consonancia con ella ${ }^{11}$.

Pecaríamos de poco caritativos si no volviéramos a insistir en algo que ya se dijo antes: simplemente no es cierto que la doctrina judicial niegue cualquier tipo de elemento valorativo en el procesamiento y sanción de la legislación de emergencia (cfr. supra, nota núm. 5). Pero como aquí solo interesa lo que sucede en lo que la doctrina llama la etapa constatativa del presupuesto habilitante que acompaña a la declaración, la objeción se mantiene en pie. Concretamente en lo relativo a la condición a) de la fórmula, hasta donde sé la única explicación que la doctrina puede esgrimir de que sea la propia autoridad política la que deba realizar la constatación - y no una entidad alternativa- ha de apelar, en última instancia, al mero arbitrio del constituyente. Vistas así las cosas, la conclusión que se sigue es que (E') no parece estar en condiciones de ofrecer una definición objetiva del presupuesto habilitante que resulte conciliable con una interpretación integral y coherente de lo que debería suceder entre los actores que intervienen en un ordenamiento jurídico cuando el instituto de la emergencia aflora a superficie, por lo menos no si no toma el recaudo de aclarar qué razón explica que nuestros actuales textos constitucionales realicen el tipo de distribución facultativa que efectivamente realizan.

En la segunda fórmula alternativa, las propiedades características del hecho o situación de emergencia reciben una interpretación epistémica. Veamos cómo queda reconstruida:

\section{(E”) Emergencia $=_{\mathrm{df}(\text { Doctrina } \mathrm{II})}$}

Para todo sistema normativo $\mathbf{S N}$ y ante un hecho, evento, circunstancia o situación $\mathbf{P}$, extrínsecamente dotado de $\mathbf{N}$ propiedades o modos de ser característicos, $\mathbf{P}$ constituye objetivamente una situación de emergencia $\mathbf{E}$ si y solo si: a) la autoridad normativa $\mathbf{X}$ la instituye o declara como tal; $b$ ) no se constatan vicios desde el punto de vista formal; $\mathrm{y} c$ ) dentro del universo de propiedades o modos de ser característicos que $\mathbf{P}$ posee extrínsecamente, $\mathbf{P}$ reúne precisamente aquellas propiedades que la ley fija como presupuestos fácticos de la emergencia, más allá de cuáles sean las evaluaciones pertinentes de la autoridad normativa $\mathbf{X}$.

Como se intuirá, el problema que suscita una interpretación semejante no es ya el de que falle en explicar el papel que la constitución le adjudica a la autoridad política, como sucedía con la interpretación anterior. El problema revestiría una gravedad aún

11 En la literatura reciente se han propuesto al menos dos modelos teóricos que creen plausible destinar la función de constatación y convalidación de la emergencia a un organismo administrativo especial, como un $F e$ deral Emergency Board u otros análogos. Al respecto, vid. LEVINSON y BALKIN, 2010 y, en especial, GOODMAN, 2010. En el modelo defendido en este último trabajo, el comité independiente funciona sobre la base del «principio de hetero-investidura» [heteroinvestiture principle], según el cual la parte que declara la emergencia debe ser completamente independiente de la parte que gana poder con ella (2010: 1278-1279). No obstante, el punto sobre el que este trabajo seguiría sin arrojar luz suficiente (al menos hasta donde tuve ocasión de comprobar) es el de la capacidad de iniciativa que tendría este organismo a la hora de constatar y declarar la emergencia. En otras palabras, ¿tan solo podría actuar a petición expresa de la autoridad política o estaría dotada de iniciativa propia? El silencio sobre este interrogante que se percibe en este y otros trabajos creo que es sintomático de las dificultades que exhibe todo intento de construir un sistema institucional de pesos y contrapesos [checks and balances] que no se haga pasible de la objeción contra-mayoritaria ( $c f r$. WALDRON, 2014). Sobre la inviabilidad de aplicar esta propuesta en países sudamericanos como Argentina, vid. RosENKRANTZ, 2011: 1583-1584. 
mayor. Abrazando una interpretación semejante, la doctrina se arriesga peligrosamente a incurrir en una posible contradicción, a saber: la que se daría entre seguir asumiendo, por un lado, el compromiso radical con la asepsia valorativa que es tan significativo para ella; y tener que admitir, por otro lado, que la constatación de una propiedad extrínseca necesariamente involucra la asunción de algún posicionamiento valorativo.

Con todo, tal vez sea posible evitar la contradicción. Sobre el telón de fondo compuesto por las definiciones introducidas en la sección 4.1, podríamos ahondar más y decir que si bien una propiedad es extrínseca cuando su ontología es subjetiva, «subjetividad» no necesariamente implica «subjetividad valorativa». Así, aunque solo sea por retomar el ejemplo favorito de SEARLE, lo que hace que este trozo de papel azulino cuente como un billete de 20 euros se explica por la asunción de una actitud intencional de cierto tipo, no por la adopción de un punto de vista valorativo (cfr. supra). Son reglas constitutivas, además, las que fijan el grado de adecuación de la actitud; y, aunque para existir, dichas reglas dependen a su vez de otra serie de actitudes intencionales, estas actitudes intencionales tampoco tienen por qué comportar la asunción de una determinada perspectiva valorativa, excepto tal vez de modo muy indirecto ${ }^{12}$. De manera que si esta fuera la perspectiva explicativa que cabe asumir para dar cuenta de las propiedades extrínsecas e institucionales que están en cuestión a la hora de constatar objetivamente la presencia de una situación de emergencia, las valoraciones no parecen constituir una amenaza.

No obstante esta salvedad, recuérdese la distinción entre hechos o fenómenos «institucionales»y «sociales» trazada asimismo en la sección 4.1. A diferencia de los hechos institucionales, los hechos sociales pueden existir sin que nadie sea consciente de ellos. Constata SEARLE en Making the Social World que «una economía podría ingresar en una recesión o atravesar las etapas de un ciclo económico sin que los miembros de la comunidad tengan siquiera los conceptos de recesión o ciclo económico» (2010: 116; cfr. supra, nota núm. 7). Ahora imaginemos que un juez de una comunidad tal se dispone a revocar una declaración de emergencia promulgada por la autoridad política apelando a un concepto o propiedad «social» que hasta ese momento careciera de reconocimiento expreso por parte de los miembros de dicha comunidad. ¿No sonaría ciertamente jactancioso de su parte? En contrapartida, imaginemos que no es el juez sino la propia autoridad política la que decide hacer lo mismo para respaldar una declaración de emergencia. Así, por ejemplo, la autoridad apela a un concepto de recesión como el marxista que emplea MENDEL (cfr. supra), pero que hasta ese momento no gozaba de crédito alguno. La jactancia probablemente sea comparable, aunque no sus implicancias anti-democráticas. Pareciera, pues, que ante porciones de la realidad de decodificación conceptual al menos polémica, el margen de libertad discursiva del que disponen los poderes del Estado es marcadamente desigual. Los presupuestos habilitantes en los que descansan las declaraciones de emergencia carecen de tipifica-

${ }^{12}$ Lo que suele estar detrás es una convención arbitraria en el sentido de LEWIS, 1986: 16-24. La regla constitutiva según la cual «X cuenta como dinero para $\mathrm{Y}$ en $\mathrm{S}$ » tan solo busca resolver un problema de coordinación para el cual probablemente muchas otras cosas que no sean $\mathrm{X}$ podrían desempeñarse igualmente bien. De allí la arbitrariedad de la solución propuesta. La única valoración posible que subyacería detrás de la convención es la valoración relativa a la necesidad de solucionar un problema existente. Al respecto, vid. PUTNAM, 1983: 174-175. 
ción legal específica. Luego, no habiendo nada semejante, la autoridad judicial siempre estará obligada a correr en desventaja.

\section{6. ¿UNA SALIDA ALTERNATIVA?}

A la hora de aludir al requisito doctrinario y jurisprudencial predominante en Latinoamérica diciendo que «el presupuesto habilitante debería construirse siempre en términos puramente fácticos (esto es, no valorativos)», adviértase que nunca se mencionó la instancia concreta a la cual va dirigida el predicado deóntico. En cierto sentido esto parece innecesario, pues resulta casi una trivialidad que se trata del Poder Ejecutivo. De dirigirse a cualquiera de los otros poderes, tanto al Poder Legislativo como al Poder Judicial les sería perfectamente factible construir el presupuesto habilitante en términos puramente fácticos; para ello, bastaría con que refirieran descriptivamente a las valoraciones de la autoridad política. Pero claramente no es esto lo que estipula el requisito. ¿Qué sucedería, sin embargo, si el requisito se interpretara precisamente en esta liza, pero sin reemplazar al destinatario de la orden?

En Prueba y verdad en el derecho, remitiéndose a los enunciados judiciales que incorporan términos valorativos como «grave» $\mathrm{u}$ «obsceno» («emergencia» podría ser otro de ellos), Jordi FERRER diferencia entre aquellos enunciados que participan de la valoración realizada por el Legislador y aquellos otros que simplemente se limitan a constatar que un hecho o situación es valorada por el Legislador y/o la comunidad de cierta manera (por ejemplo, como algo grave, obsceno o urgente, digamos) ( $c f r$. 2005: 51-3). Esto nos lleva, entonces, a diferenciar entre el uso de una expresión valorativa y su mención, o entre la adopción de una perspectiva externa y la adopción de una perspectiva participante, lo cual genera importantes repercusiones a la hora de interpretar el requisito en cuestión ${ }^{13}$. Suponiendo que todo lo que él demande se leyera ahora como una exigencia para que el Poder Ejecutivo tan solo se limite a describir las valoraciones de la población a la que representa, sin por eso tener que compartirlas, el presupuesto habilitante podría construirse empleando juicios descriptivos o constatativos que incluyan términos valorativos pero que al mismo tiempo lo eximan de la actividad de «valorar».

En lo que sigue, deseo demostrar en un argumento de tres pasos por qué esta interpretación del requisito resultaría inaceptable. Inspirados en el razonamiento tripartito que suele atribuírsele al sofista GORGIAS, podríamos resumir el argumento de la siguiente manera:

- Paso 1: Así interpretado, el requisito podría imponer una restricción absurda desde el punto de vista práctico.

- Paso 2: Si el requisito no fuera absurdamente restrictivo, sería incompatible con nuestras mejores intuiciones sobre la dinámica de la representación política.

- Paso 3: Si el requisito fuera compatible con nuestras intuiciones políticas, sería incoherente o innecesario.

13 Sigo en este sitio la terminología empleada por B. WILLIAMS en «Conocimiento, ciencia, convergencia», el octavo capítulo de La ética y los límites de la filosofía (vid. en especial WILLIAMS, 1997: 181-5). 
Paso 1. Supongamos que un evento $\mathbf{X}$ de cierto tipo (por ejemplo, un acto de vandalismo que destruyera un monumento o una estatua $\mathbf{E}$ a la que mucha gente considera $\mathbf{S}$-i. e. «sagrada») generara el riesgo de dejar en una sensación de humillación $\mathbf{H}$ sin precedentes a una parte importante de la población $\mathbf{P}$. Tanto el término $\mathbf{S}$ como el término $\mathbf{H}$ actúan como predicados éticos (densos) de indudable contenido valorativo. Si la exigencia doctrinaria implica aceptar tan solo el empleo descriptivo de este tipo de predicados por parte del Poder Ejecutivo, este solo podría decir « $\mathbf{X}$ representa una situación de Emergencia, entre otras cosas, porque $\mathbf{E}$ es $\mathbf{S}$ según $\mathbf{P}$ y $\mathbf{X}$ genera $\mathbf{H}$ en $\mathbf{P} \gg$. Si se acepta esta lectura reconstructiva del requisito, se deben aceptar las siguientes proposiciones:

- Existe la posibilidad de que el Poder Ejecutivo comprenda de qué manera $\mathbf{E}$ es $\mathbf{S}$ según $\mathbf{P}$ y $\mathbf{X}$ genera $\mathbf{H}$ en $\mathbf{P}$.

- Si existe esta posibilidad y esta posibilidad se cumple, el Poder Ejecutivo podrá decir autorizadamente que $\mathbf{E}$ es $\mathbf{S}$ según $\mathbf{P}$, esto es, que es verdadero que $\mathbf{E}$ es $\mathbf{S}$ según $\mathbf{P}$, y también que es verdadero que $\mathbf{X}$ genera $\mathbf{H}$ en $\mathbf{P}$.

- E puede ser $\mathbf{S}$ según $\mathbf{P}$; $\mathbf{X}$ puede generar $\mathbf{H}$ en $\mathbf{P}$; y el Poder Ejecutivo puede reconocer que $\mathbf{E}$ es $\mathbf{S}$ según $\mathbf{P}$ y que $\mathbf{X}$ puede generar $\mathbf{H}$ en $\mathbf{P}$, pero aun así sostener que $\mathbf{P}$ se equivoca.

- Para que el Poder Ejecutivo pueda decir que «E es $\mathbf{S}$ según $\mathbf{P} »$ pero que «P está equivocado», pues «E no es $\mathbf{S}$ », no puede ser el caso que $\mathbf{E}$ no sea $\mathbf{S}$ porque el Poder Ejecutivo posea una escala valorativa diferente a la de $\mathbf{P}$, ya que aquí no se estaría hablando de la verdad o falsedad de que $\mathbf{E}$ es (no es) $\mathbf{S}$; se estaría hablando de que $\mathbf{E}$ se caracteriza por una propiedad distinta (S', por ejemplo).

- Luego, una de las maneras en las que $\mathbf{E}$ puede no ser $\mathbf{S}$ y $\mathbf{P}$ estar equivocado en sostener que «E es $\mathbf{S} »$, es que $\mathbf{E}$, tal cual es entendido por $\mathbf{P}$, implique proposiciones empíricas (no valorativas) falsas que el propio $\mathbf{P}$ pueda - al menos en principio- reconocer como tales. En nuestro ejemplo, considerar que $\mathbf{E}$ previene las invasiones extranjeras, digamos, o evita las inundaciones, conformando estas consideraciones una parte de lo que explica la propiedad $\mathbf{S}$ de $\mathbf{E}$, implicaría precisamente sostener proposiciones empíricas falsas (sobre lo mismo, vid. Williams, 1997: 181 y ss.).

- Si esto es así, el requisito podría entenderse como obligando al Poder Ejecutivo a mencionar $\mathbf{S}$ (y quizá también $\mathbf{H}$ ) tal como $\mathbf{P}$ lo usa, incluso si « $\mathbf{E}$ es $\mathbf{S}$ » conlleva implicancias fácticas falsas y $\mathbf{P}$, en efecto, se halla en un error flagrante.

Consecuencia: así interpretado, el requisito se transforma en absurdo desde el punto de vista práctico, ya que, a excepción de algunas circunstancias, no se aprecia qué beneficios sociales podría comportar una exigencia semejante. Si bien es cierto que a veces los beneficios de actuar favoreciendo el punto de vista valorativo de una comunidad serán evidentes (en nuestro caso imaginario, no declarar una emergencia destinada a perseguir a los vándalos que destruyeron la estatua podría resultar mucho más perjudicial que declararla: por ejemplo, la población podría levantarse en armas para encontrar a los culpables), en otras circunstancias la prospección será justamente la inversa. ¿Qué pasaría, por ejemplo, si ante el deterioro de la estatua, la población $\mathbf{P}$ comenzara a temer seriamente por la invasión de una potencia extranjera, cuando este peligro resulta inexistente? ¿Debería la autoridad política declarar una emergencia de tipo militar, imponiendo toques de queda o destinando parte del presupuesto estatal a 
construir bunkers de guerra o a iniciar una carrera armamentística? Difícilmente semejante dispendio de recursos resulte justificable.

Paso 2. El requisito podría interpretarse de la misma manera pero con una salvedad: si los predicados valorativos que detenta una población solo pueden mencionarse, mas no usarse - es decir, si solo pueden relatarse, mas no compartirse, a la manera del observador empático de WILLIAMS ( $c f r$. 1997: 181) ${ }^{14}$ _, al menos debe estar garantizado que ellos no impliquen proposiciones empíricas falsas. Más allá de que la doctrina no parece dispuesta a abrazar un requisito así reconstruido, esta reinterpretación situaría a la autoridad política y al Poder Judicial en una posición de equidistancia con respecto a los valores de la ciudadanía.

Ahora bien, ¿por qué la autoridad política habría de estar impedida de usar términos valorativos y compartir el punto de vista de la población a la que representa? ¿No es precisamente eso lo que se pide en general de ella? Una interpretación como esta parece ignorar que la dinámica democrática de un régimen representativo de gobierno, si bien parece presuponer la posibilidad de que el poder democráticamente electo pueda figurarse o constatar los intereses y las valoraciones de los representados - para así actuar en consonancia con ellos_-, no requiere que sean exclusivamente estas valoraciones las que señalen el camino. Esto está relacionado con el principio de «prohibición del mandato imperativo», en cuya defensa explícita no ingresaré aquí por cuestiones de espacio (al respecto, vid. SÁNCHEZ, 2010).

Por otro lado, esta reinterpretación del requisito parece dar por sentado el carácter no problemático del procedimiento tendiente a descubrir cuáles son los valores sociales imperantes, ignorando además el peso que poseen los partidos políticos y las campañas electorales a la hora de llegar no solo a descubrir estos valores, sino también a crearlos y/o regenerarlos ( $c f r$. THOMPSON, 1999). En este sentido, nunca será cierto que el Poder Judicial y el Poder Político se sitúen en una posición de equidistancia epistémica con respecto a los valores que sustente una comunidad determinada.

Paso 3. Hagamos de cuenta que adoptamos mecanismos democráticos en el proceso de selección de nuestros jueces. Esto podría resultar indeseable por varias razones (al respecto, vid. GUARNIERI y PEDERZOLI, 2002), pero supongamos que sucede tal cosa, con lo que la preocupación planteada en el punto anterior es desactivada. Bajo esta óptica, el requisito se vuelve innecesario o incoherente, ya que no se alcanza a entender por qué es la autoridad política la que debe construir el presupuesto habilitante y no, por ejemplo, la propia autoridad judicial. Además, tampoco se explicaría por qué la autoridad política debiera restringirse a constatar lo que la sociedad valora y no inclinarse precisamente a valorar. Si lo que dota de legitimidad a una decisión política viene dado, entre otras cosas, por el hecho de que reúna ciertas credenciales democráticas, ¿no será porque la asunción de un punto de vista valorativo resulta consustancial a ella, sin importar sobre qué materia de la realidad verse o se pronuncie?

14 Escribe allí Williams: «Un observador empático puede seguir las prácticas de la gente que observa. Puede relatar, anticiparse, y hasta hacerse parte de las discusiones sobre el uso del concepto que esa gente emplea. Pero como sucede con otros de esos conceptos que observa, los que se relacionan con la religión, por ejemplo, o con la brujería, el observador puede en última instancia no identificarse con el uso del concepto: puede que realmente no sea un concepto suyo». 


\section{A MODO DE CIERRE: VALORACIONES, OBJETIVIDAD Y DEMOCRACIA}

Más allá de que las reflexiones formuladas a lo largo de este trabajo parecieran arrojar la conclusión de que resultaría imposible o inviable construir el presupuesto habilitante de una emergencia prescindiendo de consideraciones valorativas formuladas desde un punto de vista participante, aquí quisiera despejar este malentendido para decir que aunque dicha tarea bien puede ser perfectamente posible, ella resulta pragmáticamente innecesaria.

Por empezar, ¿por qué es posible? En pocas palabras, por la misma razón por la cual en principio es siempre posible describir cualquier cosa, hecho, evento, situación o circunstancia, evitando la utilización de términos valorativos. Lo que no es posible, sin embargo, es prescindir de consideraciones valorativas a la hora de entender la relevancia de una descripción. En el caso de aquellas descripciones que aluden a las propiedades intrínsecas que caracterizan a un hecho bruto, esto se puede ver con la ayuda de un ejemplo muy sencillo. Supóngase que un simple transeúnte escucha al pasar la siguiente oración pronunciada por un desconocido: «la bóveda en la que se encuentra la reliquia es de acero inoxidable». Incluso asumiendo que el desconocido está realizando un empleo convencional del lenguaje, ¿existe acaso una manera de que el transeúnte pueda averiguar el sentido que posee esta oración basándose tan solo en el significado que habitualmente le atribuimos a las palabras que la integran? Parece evidente que hasta no conocer el contexto práctico-normativo en el que tiene lugar el enunciado, su sentido se mantendrá como un gran interrogante.

Supóngase ahora que el transeúnte decide indagar más sobre el asunto y averigua que el desconocido en cuestión se trata de un reputado arqueólogo que trabaja para una conocida universidad. La reliquia referida en su enunciado constituye una joya muy valiosa de la Antigüedad Clásica que se hallaba desaparecida desde la última Cruzada. Consciente de estos datos, probablemente el transeúnte intuya que la descripción realizada mediante el enunciado anterior resulte relevante a los efectos de determinar «cómo abrir la puerta de la bóveda» (P1), pues esto es lo que permitiría satisfacer el interés arqueológico prevaleciente: «acceder a la reliquia»(I1). Pero imagínese que el transeúnte permanece un rato más escuchando la conversación del desconocido, quien acto seguido pasa a revelar información acerca de la presión exacta con que la puerta de la bóveda se encuentra cerrada. Su interlocutor, aparentemente un ingeniero que trabaja para su misma universidad, parece haberle sugerido que el Departamento de Ciencias Exactas dispone de un ariete hidráulico capaz de ejercer sobre la puerta de la bóveda una presión suficiente como para derribarla. En este contexto, no solo habrá variado el problema original sino también el interés prevaleciente. Mientras el nuevo problema en ciernes podría describirse como el problema de «cuánta presión ejercer sobre la puerta para derribarla» (P2), el interés podría describirse como el de «acceder a la reliquia sin importar que se dañe la bóveda» (I2). No obstante esta inferencia, la conversación entre los dos desconocidos prosigue y el arqueólogo, mediante un nuevo enunciado descriptivo, revela características muy específicas sobre el tipo de cerradura que bloquea la puerta, la cual constituye un mecanismo de alta sofisticación técnica, cuyo desarrollo en un estadio tan temprano de la historia era considerado inimaginable hasta el día de hoy. Esta nueva descripción, intuye el transeúnte, ya no responde a I1 o 
a $\mathbf{I} 2$ sino a un nuevo interés en juego: «acceder a la bóveda pero manteniéndola intacta» (I3), el cual comporta a su vez una reformulación de los dos problemas iniciales. Lo que importa ahora es «cómo abrir la puerta sin dañarla» (P3).

Téngase presente que en ninguna de las descripciones empleadas por el arqueólogo se ha aludido expresamente al interés que se encontraba en juego. Sin embargo, es claro que lo que las ha tornado relevantes y/o transparentes y, por ende, les ha dado sentido, se trata ni más ni menos que de un interés o valor operante. Este curioso fenómeno, que ha sido extensamente estudiado desde la pragmática del discurso ( $c f r$. Davis, 1991), nos permite incluso entender por qué ni siquiera las propiedades intrínsecas que caracterizarían a aquellos hechos brutos como los terremotos o las inundaciones podrían ser descriptivamente aludidas ignorando el interés prevaleciente, el cual actúa como una condición ineludible para su comprensión. Por caso, si la autoridad política decidiera referirse al número de heridos que provocó un terremoto pero omitiera aportar datos sobre el total de rutas clausuradas, probablemente ello obedezca a que considera más importante subsanar lo primero que lo segundo, o porque los recursos económicos de los que dispone el Estado son escasos. Desde ya, lo que no podría haber hecho es pronunciar juicios falsos sobre cualquiera de estos fenómenos, pero esta es otra cuestión.

Con estas aclaraciones en mente, veamos ahora qué sucede con los predicados éticos densos y algunos términos que aluden a propiedades institucionales, tales como los términos «inflación» o «recesión» que tan habitualmente emplean las autoridades políticas y los analistas sociales. ¿Qué implica dicha utilización? Poniéndolo de la manera más simple posible, implica el reconocimiento de que, no ya detrás de su utilización, sino en su utilización misma, se plasma la operatividad de un valor social o interés, el cual puede llegar a ser más o menos universal, o más o menos compartido por la ciudadanía. Así, cuando alguien describe un fenómeno social como la crisis de refugiados sirios, por ejemplo, utilizando términos como «precario» o «degradante» para referirse al tipo de campamentos en los que provisoriamente (según sería de esperar) se hallan, lo que suele estar haciendo es señalar que estos campamentos representan un problema, y que representan un problema porque transgreden algún interés o valor con el que él está comprometido. Lo mismo sucede cuando alguien emplea la expresión «alto nivel de congestionamiento» para referirse al estado de las carreteras viales de una región, y tantas otras. ¿Podría haber elegido una terminología diferente, más propiamente «intrínseca» o que no invocara términos valorativos? Por supuesto que sí, podría haberlo hecho. Podría haber optado por hablar del material en el que están construidas las tiendas de los campamentos, del tipo de camas provistas o de la humedad y el calor que allí se genera cuando llueve; del mismo modo, quien alude al estado de las rutas, podría haber optado por hablar de la cantidad exacta de vehículos por kilómetro y del tiempo que demoran los automovilistas en recorrer ciertas distancias. Sin embargo, aunque todo esto es factible, lo que se hace al obrar así es tan solo demorar para una instancia posterior la consideración del valor o interés relevante que se encuentra en juego. Justamente, los predicados éticos densos y algunas propiedades sociales tienen la virtud de permitir introducir estas valoraciones sin aplazar la consideración valorativa para una instancia posterior.

Por todo ello, pues, el requisito de reconstruir el presupuesto habilitante de una declaración de emergencia prescindiendo de todo término valorativo, si bien es de 
satisfacción posible, pareciera ser, por lo demás, innecesario. Admitida esta peculiaridad, quedaría pendiente la tarea de construir una fórmula que sea capaz de dar cuenta del control objetivo del presupuesto habilitante en materia de emergencia que no despierte las objeciones que aquí he suscitado. Una simple razón de espacio me ha obligado a posponer su abordaje para otra ocasión ( $c f r$. PARMigiani, 2016). Por eso, ya para concluir este trabajo, solo deseo remarcar que si el motivo de preocupación que se esconde detrás de la negativa del Poder Judicial latinoamericano a abrazar una fórmula de la emergencia que a la vez sea objetiva y valorativa, se explica por la posibilidad siempre latente de caer víctimas de un decisionismo político arbitrario, nada podría hacer menos por desalentar esta preocupación que la idea de un control judicial que se presuma valorativamente aséptico. Limitar la arbitrariedad política seguramente ha de traer grandes beneficios. Beneficios como estos, a su vez, conllevan importantes desafíos. El mayor de todos ellos, no obstante, sigue siendo cómo hacerlo sin trastocar las bases de la cultura democrática. Es este en cierto modo el desafío que al Poder Judicial imperante en buena parte de Iberoamérica todavía le restaría asumir incontestablemente.

\section{REFERENCIAS BIBLIOGRÁFICAS}

Agamben, G., 2007: Estado de excepción, trad. F. Costa e I. Costa, Buenos Aires: Adriana Hidalgo Editora.

Alchourrón, C., y Bulygin, E., 2002: Introducción a la metodología de las ciencias jurídicas y sociales, 4. ${ }^{a}$ reimpresión, Buenos Aires: Editorial Astrea.

ANDRÉS IBÁÑEZ, P., 1992: «Acerca de la motivación de los hechos en la sentencia penal», Doxa, Alicante, núm. 12, 257-299.

ÁvilA, H., 2012: Teoría de la seguridad jurídica, trad. L. CRIAdO SánCHEZ, Madrid: Marcial Pons.

Bourdieu, P., 2007: El sentido práctico, trad. A. Dilon, Buenos Aires: Siglo XXI Editores.

CAvell, S., 1979: The claim of reason, Oxford: Oxford University Press.

Chisholm, R., 1976: Person and Object, La Salle, Illinois: Open Court.

Ciuro CALDANI, M. Á., 2007: «El Fin Judicial de la Emergencia desde el punto de vista jusfilosófico trialista - Posibilidades de debate que aclaran el sentido del derecho», en A. A. ALTERINI (dir.), La emergencia y el caso Massa, Avellaneda (Argentina): Editorial La Ley.

Comanducci, P., 1999: Razonamiento jurídico. Elementos para un modelo, México D. F. (México): Fontamara.

Davies, S. (ed.), 1991: Pragmatics. A Reader, New York: Oxford University Press.

DEWEY, J., 2008: Teoría de la valoración. Un debate con el positivismo sobre la dicotomía de bechos y valores, trad. M. A. Di BERARDINO y Á. M. FAERnA, Madrid (España): Biblioteca Nueva.

EsQuivel, J., 1981: «Juicios de valor, positivismo jurídico y relativismo moral», Crítica: revista bispanoamericana de filosofía, 3-28.

EvANS-PRITCHARD, E. E., y GILLIES, E., 1976: Witchcraft, oracles and magic among the Azande, Oxford: Clarendon Press.

FERRAJOLI, L., 2001: «Pasado y futuro del Estado de derecho», Revista internacional de filosofía política, 17, 31-46.

Ferrer Beltrán, J., 2005: Prueba y verdad en el derecho, Madrid: Marcial Pons. 
GARgARELla, R., 2008: «Una disputa imaginaria sobre el control judicial de las leyes: El «constitucionalismo popular» frente a la teoría de Carlos Nino», en M. Alegre, R. Gargarella y C. Rosenkrantz (coord.), Homenaje a Carlos S. Nino, Buenos Aires: La Ley, 203-218.

GonZÁlez Lagier, D., 2005: «Los hechos bajo sospecha. Sobre la objetividad de los hechos y el razonamiento judicial», en D. GonzÁlEz LAGIER, Quaestio Facti. Ensayos sobre prueba, causalidad y acción, Bogotá: Palestra (Temis), 17-52.

GOODMAN, R., 2010: «Imagining a Federal Emergency Board: A Framework for Legalizing Executive Emergency Power», NYUL Rev., 85, 1263-1290.

Guarnieri, C., y Pederzoli, P., 2002: The Power of Judges. A Comparative Study of Courts and Democracy, Oxford: Oxford University Press.

Guibourg, R. A., 2003: «Norma, coyuntura y emergencia», en R. A. GuibOuRG (dir.), Emergencia económica y teoría del derecho, Avellaneda: Editorial La Ley, 5-9.

Gutmann, A., y Thompson, D., 1996: Democracy and Disagreement, Harvard, Massachusetts: Harvard University Press.

HEMPEL, C., 1979: La explicación científica. Estudios sobre filosofía de la ciencia, trad. M. FrassINETI DE GALlO et al., Buenos Aires: Paidós.

KIM, J., 1982: «Psychophysical Supervenience», Pilosophical Studies, 41, 51-70.

Langton, R., y LewIS, D., 1998: «Defining “intrinsic”», Philosophy and Phenomenological Research, 58, 333-345.

LevinSON, S., y BALKIn, J. M., 2010: «Constitutional Dictatorship: Its Dangers and Its Design», Minnesota Law Review, 94, 1789-1866.

LEWIS, D., 1983: «Extrinsic Properties», Philosophical Studies, 44, 197-200.

- 1986: Convention. A Philosophical Study, Oxford: Basil Blackwell.

MacInTyre, A., y Korbut, A., 1972: «A Mistake about Causality in Social Science», en P. LASLETT y W. G. Runciman (eds.), Philosophy, Politics and Society, Oxford: Basil Blackwell, 48-70.

MacInTyRe, A., 1977: «Is Understanding Religion Compatible with Believing?», en B. R. WILSON (comp.), Rationality, Oxford: Basil Blackwell, 62-77.

MANDEL, E., 1975: La crisis, Barcelona: Editorial Fontamara.

Martí, J. L., 2006: La república deliberativa. Una teoría de la democracia, Madrid: Marcial Pons.

Merton, R. K., 1980: Ambivalencia sociológica y otros ensayos, trad. J. L. LóPEz MuÑOz, Madrid: Espasa Calpe.

MurdoCH, I., 2001: La soberanía del bien, trad. Á. Domínguez HeRnÁndEZ, Madrid: Caparrós Editores.

Olivé, L. (comp.), 1993: Ética y diversidad cultural, México D. F.: Fondo de Cultura Económica.

OrOZCO HENRíQueZ, J., 2003: «Democracia, imperio del derecho y función jurisdiccional», en J. MAlem, J. Orozco y R. VÁzQuez (comps.), La función judicial. Ética y democracia, Barcelona: Gedisa, 295-317.

PARMigiani, M., 2016: «Hacia una fórmula objetiva de la emergencia jurídica?», en Diritto $e$ Questioni Pubbliche, vol. XVI, núm. 1, Universidad de Palermo, junio de 2016, 176-199.

PitKIN, H. F., 1984: Wittgenstein: El lenguaje, la politica y la justicia, trad. R. MONTORO RomeRO, Madrid: Centro de Estudios Constitucionales.

Putnam, H., 1983: «Convention: A Theme in Philosophy», Realism and Reason. Philosophical Papers, vol. 3, Cambridge: Cambridge University Press, 170-183.

- 2004: El desplome de la dicotomía hecho-valor y otros ensayos, trad. F. FORN I ARGIMON, Barcelona: Paidós.

RAWLS, J., 1980: «Kantian Constructivism in Moral Theory: Rational and Full Autonomy», Journal of Philosophy, LXXVII, 515-35. 
- 1993: Political Liberalism, New York: Columbia University Press.

RAz, J., 2001: «The Rule of Law and its Virtues», en Readings in the Philosophy of Law, New Jersey: Prentice Hall, 49-55.

RosenkrantZ, C., 2010: «Constitutional Emergencies in Argentina: The Romans (not the Judges) Have the Solution», Texas Law Review, 89, 1557-1586.

SÁnCHEZ, M. M., 2010: «La prohibición del mandato imperativo en el sistema electoral español», Revista Justicia Electoral, vol. 1, núm. 6, 223-238.

SEARLE, J., 1997: La construcción de la realidad social, trad. A. DOMÈNECH, Barcelona: Paidós.

- 2010: Making the social world: The structure of human civilization, Oxford: Oxford University Press.

TARUfFo, M., 2002: La prueba de los hechos, trad. J. FerRer Beltrán, Madrid: Trotta.

TAYLOR, Ch., 1997: Argumentos filosóficos, trad. F. BIRULÉs, Barcelona: Paidós.

Thompson, D., 1998, La ética política y el ejercicio de cargos públicos, trad. G. VenTUREIRA, Barcelona: Gedisa.

Tusseau, G., 2011: «The Concept of Constitutional Emergency Power: A Theoretical and Comparative Approach», Archiv für Rechts- und Sozialphilosophie, Band 97, Heft 4, Stuttgar: Franz Steiner Verlag, 498-530.

Vallentyne, P., 1997: «Intrinsic Properties Defined», Philosophical Studies, 88, 209-19.

Waldron, J., 2014: «Five to Four: Why Do Bare Majorities Rule on Courts?», The Yale Law Journal, 123, 1692-1730.

Wiggins, D., 1998a: «A Sensible Subjectivism?», en Needs, Values, Truth. Essays in the Philosophy of Value, Oxford: Clarendon Press, 185-214.

- 1998b: «Truth, Invention and the Meaning of Life», en Needs, Values, Truth. Essays in the Philosophy of Value, Oxford: Clarendon Press, 7-137.

Williams, B., 1997: La ética y los límites de la filosofía, trad. Luis CASTRO LEIVA, Caracas: Monte Ávila Editores.

Winch, P., y Bonacalza, M. R. V., 1972: Ciencia social y filosofía, trad. M. R. Vigano DE BoNACALZA, Buenos Aires: Amorrortu.

- 1994: Comprender una sociedad primitiva, trad. M. J. NiCOLAU y G. LlORENS, Barcelona: Paidósa.

Wittgenstein, L., 1967: Zettel, E. Anscombe y G. H. von Wright (eds.), California: University of California Press. 